\title{
Relative Effects of Local Disturbance and Climatic Change on Stream Ecology Over 27 Years
}

\author{
${ }^{1}$ Michael H. Paller, michael.paller@srnl.doe.gov
}

${ }^{2}$ Anna S. Knox, anna.knox@srnl.doe.gov

Environmental perturbations are increasingly global. However, most environmental studies occur at relatively small scales and for short periods because of logistical factors despite the scale dependency of ecosystem integrity. Longterm observations can reveal slow ecosystem changes that appear constant on short time scales, and large-scale observations can reveal disturbances that create ecosystem heterogeneity unobservable on small scales. We measured ecological and chemical/physical properties in five stream drainages encompassing approximately $300 \mathrm{~km}^{2}$ in the Sand Hills ecoregion of the Atlantic Coastal Plain USA starting in 1990 and continuing periodically through 2017. Streams disturbed by local anthropogenic impacts (e.g., industrial processes) and streams lacking such disturbances (termed reference sites) were sampled, the latter affected primarily by large-scale environmental processes including climate change. Jaccard similarity, Bray-Curtis similarity, and Spearman rank correlations among samples collected from the same sites over time were significantly greater at disturbed sites than reference sites, suggesting greater fish assemblage persistence and stability at the latter. The Index of Biotic Integrity (IBI), an indicator of overall environmental health, also exhibited significantly less variation over time at reference sites than disturbed sites. Chemical and physical habitat variability was greater at disturbed sites than reference sites, and this variability was directly related to temporal variability in fish assemblage structure. Climatic variations over the study period caused temporary fluctuations in fish assemblage structure at reference sites but less overall variability than at disturbed sites, nor was it associated with trends of consistent change as observed at some disturbed sites. This study demonstrated that chemical and physical changes associated with local anthropogenic disturbances resulted in increased environmental variability that was directly related to fish assemblage variability. This variability was greater than variability associated with climate change and other large-scale processes. 